\title{
OBILJEŽAVANJE 500. OBLJETNICE SENJSKE GLAGOLJSKE TISKARE - PRIGODNA POŠTANSKA MARKA I KOVANICA
}

\author{
Marin Buovac \\ Đure Basaričeka 4 \\ HR 23000 Zadar \\ marin.buovac1984@gmail.com
}

\author{
UDK: 379.8(497.5Senj) \\ 737(497.5Senj) \\ Stručni članak \\ Ur.: 2021-06-26
}

500. obljetnica osnutka glagoljske tiskare u Senju, kao itekako vrijedan kulturnopovijesni događaj, 1994. godine ovjekovječena je na filatelističkom i numizmatičkom materijalu - na službenom novcu i poštanskim markama Republike Hrvatske. Upravo filatelija i numizmatika na svojstven način svojim doprinosima i ostvarenjima uspješno otimaju zaboravu tako vrijedne događaje i obljetnice iz bogate kulturno-povijesne baštine Hrvata. Štoviše, one svojim utjecajem i ostvarenjima kao svojevrsnim propagandnim medijem uspješno populariziraju sva kulturno-povijesna bogatstva diljem zemlje i svijeta. Autor u ovome tekstu donosi prikaz ovjekovječenja tog povijesnog događaja na filatelističkom i numizmatičkom materijalu.

Ključne riječi: glagoljica, tiskara, Senj, numizmatika, filatelija

\section{Uvodne napomene}

Samo pedesetak godina nakon izuma tiskarskog stroja, na području Senja se pojavila skupina ljudi koja je shvatila vrijednost tog izuma. ${ }^{1}$ Među njima posebnu znanstvenu pozornost zaslužuje Blaž Baromić, jedna od najznačajnijih osoba hrvatske kulturne povijesti. Upravo je on 1493. godine na području Venecije tiskao brevijar koji nosi njegovo ime. Blaž Baromić se nakon tiskanja brevijara vratio u Senj i unutar godine dana nabavio potrebne strojeve za organizaciju i ustrojstvo tiskare. ${ }^{2}$ Dana 7 . kolovoza 1494. godine tiskano je prvo i najznačajnije djelo Senjske tiskare - Senjski glagoljski misal. ${ }^{3}$ Misal predstavlja knjigu u kojoj su skupljeni svi tekstovi koji se govore ili pjevaju tijekom mise cijele liturgijske

\footnotetext{
${ }^{1}$ P. RUNJE, 2008, 96.

2 P. ČEBULJ, 2020, 10; A. GLAVIČIĆ, 1994, 395, 403; A. FORTIS, 2004, 276; A. NAZOR, 2008, 104-105.

${ }^{3}$ M. BUOVAC, 2016, 2; P. ČEBULJ, 2020, 10.
} 
godine. Jezik dotičnog misala je hrvatsko-crkvenoslavenski. ${ }^{4}$ Sveukupno su sačuvana tri primjerka Misala, sva tri tiskana na papiru. Najpotpuniji primjerak čuva se u Budimpešti. ${ }^{5}$

Misal je tiskan na 216 listova, dvobojno i dvostupačno, tako da svaki stupac sadrži po 37 redaka. ${ }^{6}$ Sadrži kalendar, vlastite mise liturgijskih doba, čin mise, red mise, zavjetne i mrtvačke mise, zajedničke svetačke mise, vlastite svetačke mise, obredne tekstove, a završava kolofonom. ${ }^{7}$ Po svojim odlikama i značajkama, djela izašla iz Senjske tiskare spadaju u sam vrh europskog tiskarstva toga vremena.

500. obljetnica osnutka glagoljske tiskare u Senju ovjekovječena je na filatelističkom i numizmatičkom materijalu 1994. godine.

\section{Filatelija}

Dana 29. siječnja 1994. godine službeno je izdana poštanska marka Republike Hrvatske povodom 500. obljetnice osnutka glagoljske tiskare u Senju. ${ }^{8}$ Spomenuta poštanska marka veličine 35,5 x $29,82 \mathrm{~mm}$ i češljastog zupčanja 14 tiskana je na bijelom, gumiranom papiru u višebojnoj offset tehnici u tiskari Zrinski d.d. u Čakovcu. ${ }^{9}$ Ova poštanska marka nominalne vrijednosti tadašnjih 2200 HRD tiskana je u nakladi od 350.000 komada. ${ }^{10}$ Grafičko rješenje poštanske marke uradio je Frane Paro, akademski slikar i grafičar iz Zagreba. ${ }^{11}$ Hrvatska pošta pustila je u prodaju ujedno prigodnu omotnicu prvog dana (FDC), kao i prigodni list. ${ }^{12}$ Dotična poštanska marka bila je frankaturno važeća do 13. kolovoza 1999. godine. ${ }^{13} \mathrm{Na}$ poštanskoj marki prikazana je rekonstrukcija tiskare iz XV. stoljeća. ${ }^{14}$

${ }^{4}$ V. PUTANEC, 1985, 44.

${ }^{5}$ A. NAZOR, 2008, 94.

${ }^{6}$ A. NAZOR, 1993, 246.

${ }^{7}$ A. NAZOR, 2008, 94; P. RUNJE, 2008, 96; A. NAZOR, 1993, 246-248.

${ }^{8}$ A. GLAVIČIĆ, 1994, 404; J. LOKMER, 2014, 450; A. NAZOR, 2008, 141; J. MARAS, 2005, 33; M. BUOVAC, 2016, 2; P. ČEBULJ, 2020, 10.

${ }^{9}$ P. STRPIĆ, 2016, 152; J. MARAS, 2005, 33.

${ }^{10}$ V. ERCEGOVIĆ, 1995, 551; P. STRPIĆ, 2016, 152; J. MARAS, 2005, 33.

${ }^{11}$ A. GLAVIČIĆ, 1994, 404; P. STRPIĆ, 2016, 152; J. MARAS, 2005, 33.

${ }^{12}$ J. LOKMER, 2014, 450; J. MARAS, 2005, 33.

${ }^{13}$ J. MARAS, 2005, 33.

${ }^{14}$ A. GLAVIČIĆ, 1994, 404; P. STRPIĆ, 2016, 152; J. MARAS, 2005, 33. 


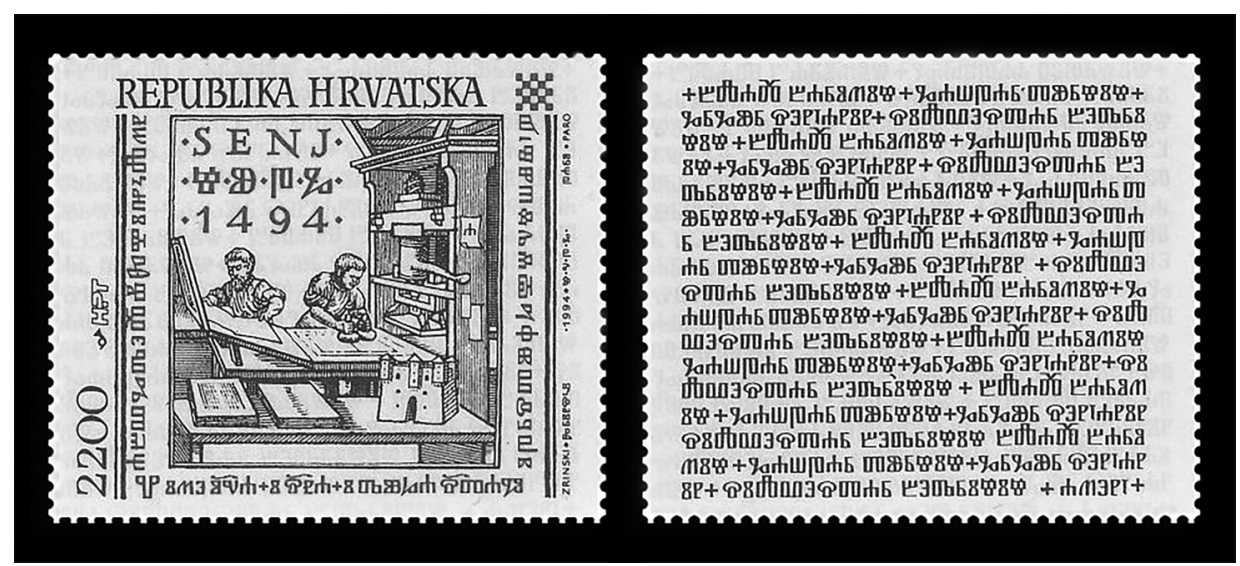

S1. 1. Poštanska marka povodom 500. obljetnice Senjskoga glagoljskoga misala ${ }^{15}$ (priredio: M. Buovac)

\section{Numizmatika}

Narodna banka Hrvatske također je izdala prigodni optjecajni kovani novac od 5 kuna u povodu spomenute 500. obljetnice tiskanja Senjskog glagoljskog misala u glagoljskoj tiskari u Senju, koju su godine 1494. osnovali tamošnji svećenici. ${ }^{16}$

Što se tiče lica, u sredini kovanice upisana je brojka "5" u kvadrat, sa strana je natpis "KUNA" (lijevo na latinici, a desno na glagoljici). Iznad brojke nalazi se grb Republike Hrvatske, a ispod grb grada Senja. Uz rub se nalazi tekst "REPUBLIKA HRVATSKA" - gore na latinici, a dolje na glagoljici. Obod ima 100 ureza. $^{17}$

Na naličju spomenute kovanice, unutar kružnice, nalazi se glagoljsko slovo "S" (S kao Senj) koje se u gornjem dijelu pretvara u knjigu s križem - Misal. Ispod Misala ispisana je godina 1494., lijevo glagoljicom, a desno arapskim brojkama. Trup glagoljskog slova "S" pretvara se u siluetu tvrđave Nehaj s tri kule. ${ }^{18}$ Unutar siluete, u dva retka, ispisan je natpis "SENJ", latinicom, a potom i glagoljicom. Desno od glagoljičnog natpisa označena je godina kovanja '94. Glagoljsko slovo "S" završava pri dnu kružnice stiliziranim motivom valova, simbolizirajući more i senjsku buru. U pojasu, koji tvori vanjski rub i rub kružnice koja omeđuje

${ }^{15}$ Izvor: https://www.posta.hr/pregled-postanskih-maraka/195?m=88 (2021-07-14)

${ }^{16}$ B. MATIĆ, 2010, 131; I. MIRNIK, 1994, 2; J. MARAS, 2005, 163; J. LOKMER, 2014, 450; A. NAZOR, 2008, 141; B. MESINGER, 1998, 79.

${ }^{17}$ B. MATIĆ, 2010, 130; I. MIRNIK, 1994, 2; J. MARAS, 2005, 163.

${ }^{18}$ Z. VIŠČEVIĆ, 2004, 36-37; I. MIRNIK, 1994, 2. 


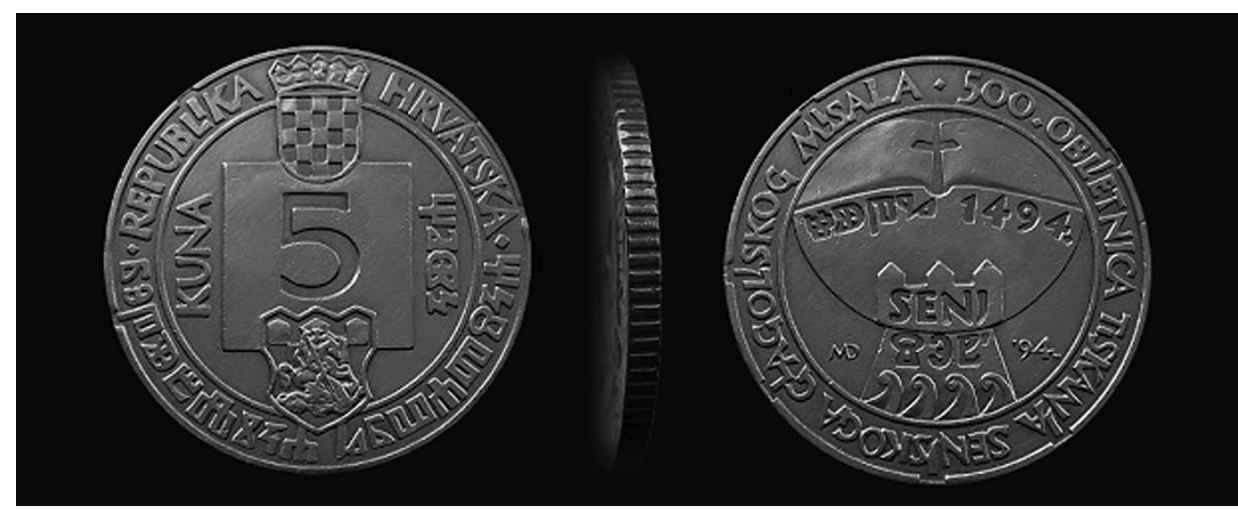

S1. 2. Avers, revers i obod prigodne kovanice iz 1994. godine ${ }^{20}$ (priredio: M. Buovac)

kvadrat kružno je ispisan natpis "500. OBLJETNICA TISKANJA SENJSKOG GLAGOLJSKOG MISALA". Pojedina slova iz teksta zadiru u vanjski rub. ${ }^{19}$

Materijal od kojeg je sačinjena kovanica u omjerima je $63,1 \%$ bakra $(\mathrm{Cu})$, $23,2 \%$ nikla (Ni) i 13,7\% cinka (Zn). ${ }^{21}$ Promjer je 26,5 mm, a masa 7,45 grama. ${ }^{22}$ Autor spomenutog likovnog rješenja je akademski kipar Damir Mataušić. ${ }^{23}$

Krajem godine, izrađen je i prigodni suvenirni zlatni kovani novac od 5 kuna, izrađen od zlata i s glatkim obodom. ${ }^{24}$ Za kraj valja napomenuti kako je prvobitno zamišljeno da se prigodni novac posvećen Senjskom glagoljskom misalu izda u nominali od 25 kuna. No, zbog štednje i kašnjenja, odlučeno je da se iskoriste postojeće rondele za 5 kuna pa je i nominala smanjena. ${ }^{25}$ Spomenuti kovani novac je pušten u optjecaj 15. srpnja 1995. godine u nakladi od 1.000.000 komada. ${ }^{26}$

195 KUNA - 500. OBLJETNICA TISKANJA SENJSKOGA GLAGOLJSKOG MISALA, Hrvatska narodna banka, URL: https://www.hnb.hr/-/5-kuna-500-obljetnica-tiskanja-senjskogaglagoljskog-misala- (2021-07-10)

20 Izvor: http://coinz.eu/hrv/1_hrk/30_kuna_5_1994_senj_missal_croatian_coins_en.php (2021-07-10)

${ }^{21}$ B. MESINGER, 1998, 115; B. MATIĆ, 2010, 130; I. MIRNIK, 1994, 2; J. MARAS, 2005 , 163; Z. VIŠČEVIĆ, 2004, 36-37.

${ }^{22}$ T. BILIĆ, 2019, 41, 48; B. MESINGER, 1998, 115; J. MARAS, 2005, 163; Z. VIŠČEVIĆ, 2004, 36-37.

${ }_{23}$ B. MESINGER, 1998, 79; B. MATIĆ, 2010, 134-135; J. MARAS, 2005, 163; Z. VIŠČEVIĆ, 2004, 36.

${ }^{24}$ I. MIRNIK, 1994, 2; J. MARAS, 2005, 172; T. BILIĆ, 2019, 56; J. LOKMER, 2014, 450. Ukupna naklada iznosi 200 komada.

${ }^{25}$ T. BILIĆ, 2019, 47.

${ }^{26}$ B. MESINGER, 1998, 79; Z. VIŠČEVIĆ, 2004, 36-37; J. MARAS, 2005, 163. 


\section{Zaključno razmatranje}

U ovom radu donesen je kratkiprikaziznimno važnoga događaja za hrvatsku povijesno-kulturnu baštinu, ovjekovječenog na filatelističkom i numizmatičkom materijalu. Riječ je o 500. obljetnici osnutka glagoljske tiskare u Senju, povodom koje je izdana prigodna poštanska marka te kovan službeni novac Republike Hrvatske. Ovdje obrađivani filatelistički i numizmatički materijal, osim svoje prvobitne funkcije, ujedno služi kao svojevrsno propagandno sredstvo, uz pomoć kojeg se mogu propagirati značajni spomenuti događaji, lokacije i pojedinci iz hrvatske povijesti. Upravo u tom kontekstu značajan je spomen i prikaz glagoljske tiskare u Senju iz 1494. godine, što je ujedno zabilježeno na filatelističkom i numizmatičkom materijalu u značajnoj nakladi, koji cirkuliraju i kolaju diljem Hrvatske i poznatoga svijeta, prenoseći vijest o bogatoj kulturnopovijesnoj baštini Hrvata.

\section{Literatura}

\section{Knjige i članci}

Tomislav BILIĆ, Kuna - 25 godina novčane jedinice Republike Hrvatske = The kuna: twenty years of the monetary unit of the Republic of Croatia, Arheološki muzej u Zagrebu - Hrvatska narodna banka, Zagreb, 2019.

Marin BUOVAC, Prikaz i značaj knjige u svijetu filatelije, Artos, 5, Osijek, 2016, 1-5.

Primož ČEBULJ, Tematska filatelija - Glagoljica, Glasonoša - list Hrvatskog filatelističkog društva Karlovac, 59, Karlovac, 2020, 8-13.

Velimir ERCEGOVIĆ, Hrvatska filatelija: od predfilatelije do maraka Republike Hrvatske, Agencija za komercijalnu djelatnost, Zagreb, 1995.

Alberto FORTIS, Put po Dalmaciji, Marjan tisak, Split, 2004.

Ante GLAVIČIĆ, Izvješće povodom obilježavanja 500. obljetnice senjske glagoljske tiskare i 300. obljetnice Vitezovićeve hrvatske državne tiskare u Zagrebu, Senjski zbornik, 21, Senj, 1994, 393-404.

Juraj LOKMER, O potrebi faksimilnih, kritičkih, digitalnih izdanja senjske glagoljske tiskare i njihove mrežne dostupnosti - razmišljanje povodom 520. obljetnice tiskanja Senjskoga glagoljskoga misala, Senjski zbornik, 41, Senj, 2014, 445-460.

Julije MARAS, Republika Hrvatska - poštanske marke i novac 2006., Filatelija d.o.o., Zagreb, 2005.

Branko MATIĆ, Hrvatska emisijska politika u segmentu kovinskoga novca, Numizmatičke vijesti, 52, 63, Zagreb, 2010, 129-144.

Bogdan MESINGER, Medaljer Damir Mataušić, Galerija "Garestin" - MGC Klovićevi dvori, Varaždin - Zagreb, 1998. 
Ivan MIRNIK, Senjske medalje Damira Mataušića / Die für Senj geprägten Medaillen von Damir Mataušić, neobjavljeni članak, Zagreb, 1994, 1-9.

Anica NAZOR, Hrvatskoglagoljske inkunabule. U povodu 500. obljetnice brevijara Blaža Baromića (1493-1993), Croatica, 23/24, 37-38-39, Zagreb, 1993, 229-257.

Anica NAZOR, Knjiga o hrvatskoj glagoljici: "Ja slovo znajući govorim...", Erasmus naklada, Zagreb, 2008.

Valentin PUTANEC, Novi prilozi za povijest hrvatskih inkunabula 15. stoljeća, Čakavska rič, XIII/1, Split, 1985, 3-56.

Petar RUNJE, Senjski kulturni krug i senjska tiskara, Senjski zbornik, 35, Senj, 2008, 91-114.

Petar STRPIĆ, Hrvatska 2016/17: Poštanske marke, Stajer-graf d.d., Zagreb, 2016.

Zlatko VIŠČEVIĆ, Kovani novac Republike Hrvatske od osamostaljenja do danas, vlastita naklada, Rijeka, 2004.

\section{Internetski izvori}

5 KUNA - 500. OBLJETNICA TISKANJA SENJSKOGA GLAGOLJSKOG MISALA, Hrvatska narodna banka, URL: https://www.hnb.hr/-/5-kuna-500-obljetnicatiskanja-senjskoga-glagoljskog-misala- (2021-07-10)

5 KUNA CROATIA (1994) MISSAL FROM SENJ, Coinz.eu, URL: http://coinz.eu/ hrv/1_hrk/30_kuna_5_1994_senj_missal_croatian_coins_en.php (2021-08-9)

500. OBLJETNICA OSNUTKA GLAGOLJSKEE TISKARE U SENJUURL: https:// www.posta.hr/pregled-postanskih-maraka/195?m=88 (2021-07-14)

\section{MARKING THE $500^{\mathrm{TH}}$ ANNIVERSARY OF THE SENJ GLAGOLITIC PRINTING HOUSE - THE COMMEMORATIVE POSTAGE STAMP AND COIN \\ Summary}

The $500^{\text {th }}$ anniversary of the founding of the Glagolitic printing house in Senj, as an exceptionally valuable cultural and historical event, was immortalised in 1994 on philatelic and numismatic material - on the official money and postage stamps of the Republic of Croatia. It is, in fact, philately and numismatics that, in a characteristic way with their contributions and achievements, are successfully preserving such valuable events and anniversaries from the rich cultural and historical heritage of the Croats. What's more, with their influence and achievements as a kind of propaganda medium, they are successfully popularising all cultural and historical treasures throughout the country and the world. In this text, the author presents the perpetuation of this historical event on philatelic and numismatic material.

Keywords: Glagolitic script, printing house, Senj, numismatics, philately 